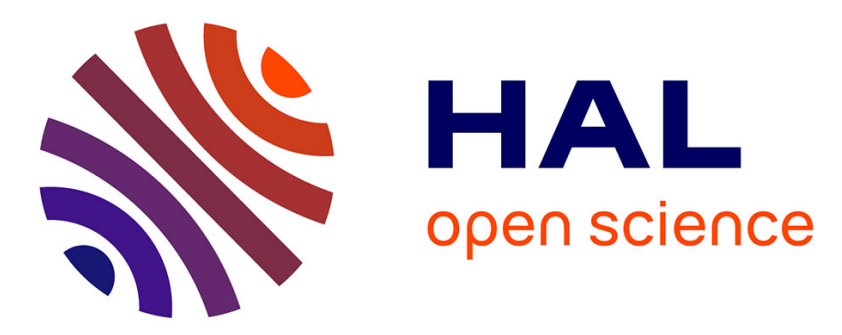

\title{
Experimental Brain Research Effects of vestibular disorders on vestibular reflex and imagery
}

Bernard Cohen, Joëlle Provasi, P. Leboucher, I. Israël

\section{To cite this version:}

Bernard Cohen, Joëlle Provasi, P. Leboucher, I. Israël. Experimental Brain Research Effects of vestibular disorders on vestibular reflex and imagery. Experimental Brain Research, 2017, 235 (7), pp.2181-2188. 10.1007/s00221-017-4959-7 . hal-02369402

\section{HAL Id: hal-02369402 https://hal.science/hal-02369402}

Submitted on 18 Nov 2019

HAL is a multi-disciplinary open access archive for the deposit and dissemination of scientific research documents, whether they are published or not. The documents may come from teaching and research institutions in France or abroad, or from public or private research centers.
L'archive ouverte pluridisciplinaire HAL, est destinée au dépôt et à la diffusion de documents scientifiques de niveau recherche, publiés ou non, émanant des établissements d'enseignement et de recherche français ou étrangers, des laboratoires publics ou privés. 


\section{Experimental Brain Research \\ Effects of vestibular disorders on vestibular reflex and imagery \\ --Manuscript Draft--}

Manuscript Number:

Full Title:

Article Type:

Funding Information:

Abstract:

Corresponding Author:

\section{Corresponding Author Secondary}

Information:

Corresponding Author's Institution:

Corresponding Author's Secondary Institution:

\section{First Author:}

First Author Secondary Information:

Order of Authors:

Order of Authors Secondary Information:

Author Comments:

Response to Reviewers:
EXBR-D-16-00713R1

Effects of vestibular disorders on vestibular reflex and imagery

Research Article

The aim of this study was to establish the effect of vestibular lesion on vestibular imagery. Subjects were required to estimate verbally their passively travelled rotation angles in complete darkness, i.e., to activate vestibular imagery. During motion the Vestibulo-Ocular Reflex (VOR) was measured. Thus we examined the coherence between the vestibulo-ocular reflex and self-rotation imagery, with vestibular-lesioned patients and healthy participants.

Unilateral acute and chronicle patients, bilateral patients and healthy subjects were compared. The stimulus was a sequence of eight successive passive rotations, with four amplitudes (from $90^{\circ}$ to $360^{\circ}$ ) in two directions.

The VOR gain was lower in patients with unilateral lesions, for ipsilateral rotations. The healthy subjects had the highest gain and the bilateral group the lowest, on both rotation sides. Thanks to vestibular compensation after acute unilateral neuritis the VOR gain increased in lesion side and decreased in healthy side, resulting in a similar gain in both sides.

A deficit of vestibular imagery was found exclusively in patients with bilateral hyporeflexia, on both sides. The performance in vestibular imagery was good in the control group and correct in the unilateral patients.

Finally we found a significant correlation between the efficiency of the VOR and that of vestibular imagery, exclusively in the bilateral patients.

The present study shows the complex relationship between vestibular imagery and the VOR. This imagery test contributes to another assessment of the spatial handicap of vestibular patients. It seems particularly interesting for patients with bilateral canal paresis and could be used to confirm this diagnosis.

Isabelle ISRAEL, PhD

CNRS

PARIS, FRANCE

\section{CNRS}

\section{Bernard Cohen, Dr.}

Bernard Cohen, Dr.

Joëlle Provasi, PhD

Pierre Leboucher, Dr.Ing.

Isabelle Israël, $\mathrm{PhD}$

No conflict of interest

Response to the reviewer \#2: of Manuscript EXBR-D-16-00713 entitled « Effects of vestibular disorders on vestibular reflex and imagery » by Cohen et al.

1. Materials and Methods

The Material and Methods section has been rearranged with all the sub-sections that 
you indicated.

The 1 rst paragraph page 5 has been corrected as you suggested, thank you !

The consent has been moved in the material/subjects sub-section.

The familiarisation paragraph is now in the paradigm description.

Information about the participants and patients recruitment has been added, and a new table completes this description.

The eye movements recording equipment is now described in the set-up section, as well as the head support, and the slow phase analysis of the nystagmus is indicated in the data analysis section.

We now used a repeated measures ANOVA for the VOR and the VIR gains, which is indeed more reliable to compare several groups with different variables !

It was added in the data analysis that the Spearman non-parametric correlation was used, at the end of a new statistical analysis section. The correlation paragraph in the results has been much reduced.

\section{Results}

The section on VOR gain has been shortened to one page and one Fig.

The VIR paragraph has also been shortened and the stimulus-response correlation chapter was removed.

The correlation between VOR and VIR has been greatly simplified and shortened. But a paragraph on coefficient of variation has been added...

\section{Discussion}

In the first paragraph of the discussion, there is now a summary of the results. Then the VIR is discussed, followed by the correlation and differences between VIR and VOR, and the VOR is analysed only at the end, as you recommended.

The dissociated mechanisms in imagery and vestibular reflex are discussed together with recent literature on vestibule and cognition. 


\section{B.S. Cohen ${ }^{1}$, J. Provasi ${ }^{2}$, P. Leboucher ${ }^{3}$, I. Israë ${ }^{4}$}

1 Service ORL, Hôpital Saint-Antoine-UPMC, 46 Bld Raspail, 75007 Paris 2 Laboratoire CHArt, EPHE-PSL, 4-14 rue Ferrus, 75014 Paris 3 PRISME, ICM, CNRS UMR 7225, Hôpital Pitié-Salpêtrière, 75013 Paris 4 Laboratoire Cognac G, CNRS UMR 8257, 45 rue des Saints Pères, 75006 Paris

Corresponding author :

Isabelle Israël

Laboratoire Cognac-G, CNRS

45 rue des Saints Pères

75006 Paris

isabelle.israel@bbox.fr

Tel : 0634393558 


\begin{abstract}
The aim of this study was to establish the effect of vestibular lesion on vestibular imagery. Subjects were required to estimate verbally their passively travelled rotation angles in complete darkness, i.e., to activate vestibular imagery. During motion the Vestibulo-Ocular Reflex (VOR) was measured. Thus we examined the coherence between the vestibulo-ocular reflex and self-rotation imagery, with vestibular-lesioned patients and healthy participants.

Unilateral acute and chronicle patients, bilateral patients and healthy subjects were compared. The stimulus was a sequence of eight successive passive rotations, with four amplitudes (from $90^{\circ}$ to $360^{\circ}$ ) in two directions.

The VOR gain was lower in patients with unilateral lesions, for ipsilateral rotations. The healthy subjects had the highest gain and the bilateral group the lowest, on both rotation sides. Thanks to vestibular compensation after acute unilateral neuritis the VOR gain increased in lesion side and decreased in healthy side, resulting in a similar gain in both sides.

A deficit of vestibular imagery was found exclusively in patients with bilateral hyporeflexia, on both sides. The performance in vestibular imagery was good in the control group and correct in the unilateral patients.

Finally we found a significant correlation between the efficiency of the VOR and that of vestibular imagery, exclusively in the bilateral patients.

The present study shows the complex relationship between vestibular imagery and the VOR. This imagery test contributes to another assessment of the spatial handicap of vestibular patients. It seems particularly interesting for patients with bilateral canal paresis and could be used to confirm this diagnosis.
\end{abstract}

Keywords : vestibular disorders; self-motion perception; cognitive task; spatial imagery; 


\section{Introduction}

The vestibulo-ocular reflex (VOR) keeps gaze stabilized in space during head movements. This apparently simple reflex (Collewijn 1989) has been extensively investigated, for example with patients suffering and recovering from vestibular disorders (Allum and Ledin 1999, Fetter and Dichgans 1990, Maire and Van Melle 2000). Vestibular input contributes directly to the VOR but also to non-reflexive perceptual responses including body orientation (Guedry 1974, Young 1981). In comparison, less is known about the vestibulo-perceptual system, probably because the vestibular organs (semi-circular canals and otoliths) are never stimulated alone, but always together with the tactile and proprioceptive system.

Moreover the relation between the VOR state and the complaints of vestibular patients is weak, according to Okada et al. (1999). We then wanted to find another test of vestibular function, closer to the patients problems. The vestibular system is actually the main idiothetic organ involved in path integration, i.e. keeping track of our own changes in orientation and position using self-motion cues (Mittelstaedt and Mittelstaedt 1980; Etienne and Jeffery 2004). Therefore the vestibular system plays a crucial role in navigation and spatial orientation (Israël et al. 1996). Self-motion perception dysfunction and imbalance in case of vestibular lesion is becoming well described (Nakamura and Bronstein 1995, Cousins et al. 2013), but less is known about vestibular spatial navigation.

Two main types of experiments have been led about vestibular perception or orientation :

1: pointing responses with the eyes or the whole-body itself (Metcalfe and Gresty 1992, Kanayama et al. 1995, Nakamura and Bronstein 1995), or with various devices indicating body orientation or velocity like button, tachometer, joystick (Okada et al. 1999, Seemungal et al. 2004, Cousins et al. 2013, Kyriakareli et al. 2013 and Tremblay et al. 2013).

2: "purely cognitive" responses (verbal magnitude estimate, reported perception) without pointing (Becker et al. 2000, Merfeld et al. 2005, Mergner et al. 1996, Cohen and Israël 2004). 
Although for some authors self-motion estimation is perception (Mergner et al. 1996, Becker et al. 2000), we believe that verbal estimate of motion magnitude or velocity is different from self-motion perception. Motion reproduction or return may be perception, but not magnitude estimate : the cognitive transduction from perception to its report in degrees or meters makes the difference, and this needs an internal representation (that self-motion reproduction does not need), i.e., imagery. Spatial navigation is "more cognitive" than perception, and it corresponds to one of those nowadays established higher vestibular functions (Besnard et al. 2015, Bigelow and Agrawal 2015, Lopez et al. 2012, Lopez 2013).

Our hypothesis is that there is an effect of vestibular lesion on vestibular imagery, through damaged processing of self-motion information (acceleration, velocity and/or amplitude). Thus we examined with vestibular-lesioned patients and healthy participants how the vestibulo-ocular reflex (which indicates disorders) matches self-rotation imagery (or in other terms, how vestibular action matches cognition (Merfeld et al. 2005)). 


\section{Material and Methods}

Subjects

We recorded 4 groups of vertigo patients (Table 1) :

Among the patients visiting a specialized medical consultation because of dizziness and/or postural instability, 4 groups of patients were selected for this retrospective study, after interrogation, physical examination, videonystagmography including oculomotor tests and checking for spontaneous or provoked nystagmus, rotatory tests with the analysis of VOR gain by cumulated slow phases, caloric test with cumulated slow phases velocity and also peak eye velocity. Patients with central signs (otoneurologic tests, MRI) were excluded.

* dizzy patients with Bilateral Canal Paresis (BilCP), in the caloric test (sum of the 4 responses lower than $20 \%$ : Baloh et al. 1984) and in traditional rotary test (VOR gain < 0.2).

* patients exhibiting disabling vertigo since less than eight days : Acute Unilateral Canal Paresis (AcUCP), defined as a canal paresis superior to $80 \%$ in the caloric test according to Jongkees formula.

* patients visiting after acute neuritis, more than three months before, because of persistent dizziness and without recovery at the caloric test : patients with Chronic Unilateral Canal Paresis (ChUCP).

* patients with no vestibular symptom revealed by otoneurologic investigation considered as the Control Group (CG). The asymmetry between both sides computed with the Jongkees formula was lower than $25 \%$ and the directional preponderance was lower than $2 \%$.

All the participants gave their written informed consent according to the guidelines of the hospital ethics committee. 
Set-up

A motorized rotating chair was used, driven by a PC computer controlling angular position and velocity, recorded at $100 \mathrm{~Hz}$ (see Israël et al. 2006).

A video nystagmography helmet (VNG Ulmer, Synapsys) was used to record the horizontal movements of one eye lit by infrared light. Sampling frequency of the camera was 25 images/s. The subject was seated, the head forward tilted of $30^{\circ}$, leaning against a head rest individually adjusted. The test started with calibrating of eye position through saccades, during about 20 seconds. The subjects also wore a headphone to mask external auditory cues.

Paradigm

The seated subjects were passively rotated around the vertical axis in complete darkness.

All subjects were submitted to the same sequence of 8 successive trials in clockwise (CW) and counter-clockwise $(\mathrm{CCW})$ directions $\left(90^{\circ} \mathrm{CW}, 180^{\circ} \mathrm{CCW}, 270^{\circ} \mathrm{CW}, 360^{\circ} \mathrm{CCW}\right.$, $90^{\circ} \mathrm{CCW}, 180^{\circ} \mathrm{CW}, 270^{\circ} \mathrm{CCW}$ and $360^{\circ} \mathrm{CW}$ ). The task was to estimate the rotated angle and verbally give its magnitude after each trial. The velocity profile was trapezoid, with $70^{\circ} / \mathrm{s}^{2}$ acceleration and $60 \%$ s plateau velocity. Plateau duration increased with increasing angle.

The experimental test was preceded by a demonstration of some stimuli and a familiarization phase of how to verbally indicate the imposed rotation angles (either in degrees or in quarter-turns). Three or four trials were presented, until the participant felt confident with the procedure.

We waited about $40 \mathrm{~s}$ between successive trials (until extinction of the post-rotatory nystagmus). With only eight successive bidirectional rotations there is no habituation of the VOR and of vestibular sensations which can be observed after a hundred angular velocity steps (Clement et al., 2008), and this same number of rotations was used by Cousins et al. (2013). 
Data analysis

The analysis of this vestibular imagery task was performed off-line through its gain : VIR (Vestibular Imagery Response) gain = estimated angle / travelled angle.

The nystagmus during the tests was recorded for each subject and each trial, thus the gain of the VOR (maximal eye velocity of slow phases minus spontaneous nystagmus velocity divided by maximal chair velocity) was calculated.

Since our hypothesis was that a canal lesion would impair both reflexive and cognitive performances, we compared the intact and disordered sides (2) of all groups (4). Therefore we applied a repeated measures ANOVA over these 4 groups to both the VOR gain and the VIR gain, separately. The responses to the ipsilesional side (IL, for CW rotations in unilateral right-lesioned patients and for CCW rotations in left-lesioned patients) and the contralesional side $(\mathrm{CL}$, for $\mathrm{CCW}$ rotations in right-lesioned patients and $\mathrm{CW}$ rotations in left-lesioned patients) of the patients groups were thereafter compared.

ANOVA was applied on the means and also on the standard deviations (SDs) of the means of the same groups and sides.

After the analysis of the effects of vestibular disorders on the VOR and on the VIR, we intended to reveal the relationship between both gains. A Spearman non-parametric rank correlation was applied over the VOR gain and the VIR gain, so that it could be computed for the different groups, on the two ipsilateral and contralateral sides separately and/or pooled. 


\section{Results}

\section{VOR gain (Fig.1)}

The ANOVA on mean VOR gain over all trials of all groups yielded a significant main effect of group $(F(3,52)=24.37, p<0.0001)$.

The post hoc analysis (Tukey) revealed that CG had the highest gain $(0.61 \pm 0.19)$ compared to AcUCP, ChUCP and BilCP ( $p=0.02,0.002$, and 0.0001, respectively). BilCP gain was lower than AcUCP and ChUCP ( $p=0.0005, p=0.0003$, respectively), but AcUCP was not different from ChUCP.

ANOVA revealed also a significant effect of side $(F(1,52)=17.63, p=0.00011)$, as the mean VOR gain of the IL, i.e., the lesioned side was lower than that of the CL side.

ANOVA finally showed a significant interaction between group and side $(F(3,52)=$ $18.75, p<0.0001)$ which was due to exclusively one group : the acute unilateral group, which had different ipsilateral $(0.27 \pm 0.09)$ from contralateral $(0.49 \pm 0.15)$ gains (post hoc Tukey, $p=0.00013)$. With the other groups (ChUCP, BilCP, CG) no different VOR gains between IL and CL were observed ( $p=0.21 ; p=0.87, p=0.98$, respectively).

Comparing the VOR gains of the AcUCP and ChUCP groups, it was found that the VOR IL mean gain tended to improve (it became higher from AcUCP : $0.27 \pm 0.09$ to ChUCP : $0.36 \pm 0.17, p=0.0002$ ) while the CL side gain slightly worsened (it decreased from AcUCP : $0.49 \pm 0.14$ to ChUCP : $0.41 \pm 0.20, p=0.0132$ ) during compensation.

There was also a significant difference between the VOR gain SDs of the different groups $(F(3,52)=4.69, p=0.0057)$, with the SDs exhibiting a similar pattern of group effect as the means. However there was no main effect of side on the VOR gain SDs $(F(1,52)=$ $0.25, p=0.62)$, unlike with the means. But there was a significant group $\mathrm{X}$ side interaction on the SDs $(F(3,52)=3.52, p=0.02)$, due to BilCP IL gain SD lower than that of ChUCP IL and of CG IL ( $p=0.04$ and 0.032 , respectively). 


\section{VIR gain (Fig.2)}

The angle estimation or vestibular imagery response (VIR) gain, i.e., the ratio between the estimated angle amplitude and the chair rotation amplitude, was then computed and analysed.

The ANOVA on mean VIR gain over all trials of all groups yielded a significant main effect of group $(F(3,52)=9.31, p=0.00005)$. So the different patients groups had different mean VIR gains.

The post hoc Tukey test showed that the VIR gain of the BilCP group was clearly and significantly lower than all the other groups gains $(p=0.005$ for AcUCP, $p=0.00023$ for ChUCP, and $p=0.00033$ for CG), while these other groups were not significantly different from each other. Indeed, as can be seen on the Fig.2, the mean VIR gains of the BilCP group were around 0.6 while the other groups were close to 1 . On the VIR gain there was no main effect of side $(F(1,52)=0.28, p=0.6)$ nor interaction between side and group $(F(3,52)=1.3$, $p=0.29$ ). This result is distinct from the VOR gain, where the AcUCP group had different IL and CL gains.

Finally, there was no main effect of group on the VIR gain SDs $(F(3,52)=1.58, p=$ $0.20)$, neither main effect of side $(F(1,52)=0.016, p=0.90)$ nor group $\mathrm{X}$ side interaction $(F(3,52)=1.04, p=0.38)$.

\section{VOR vs VIR gains (Fig.3)}

The differences and also the correlations between VOR gain and VIR gain were thereafter examined.

It was first noted that the mean VOR gain was significantly lower than the mean VIR gain $(F(1,52)=239.39, p<0.0001)$. This was the case for all groups $(F(3,52)=1.69, p=$ $0.18)$, and both sides $(F(1,52)=1.89, p=0.17)$. 
Then the correlation between the VOR gain and the VIR gain was computed for each group of subjects, including all the individual responses. It was revealed that exclusively the BilCP group exhibited a significant correlation $(r=0.225$, two-tailed $p=0.027)$.

We ultimately computed the coefficients of variation ( $\mathrm{SD} /$ mean) of both these gains, in order to be able to safely compare the means (Fig.3). ANOVA on the coefficient of variation of the VOR gain over all groups was highly significant $(F(7,104)=6.61, p<$ 0.0001). This was due on the CL side to the coefficient of BilCP (56 $\pm 49 \%)$ larger than AcUCP, ChUCP, and CG (Tukey test, $p<0.001$ for each). ANOVA on the VIR gain coefficient was also highly significant $(F(7,104)=5.95, p<0.0001)$, and the post-hoc Tukey test indicated on the CL side that the coefficient of BilCP $(51 \pm 27 \%)$ was larger than AcUCP $(p<0.05)$, ChUCP $(p<0.001)$, and CG $(p<0.001)$. The coefficient of BilCPIL $(43 \pm 22 \%)$ was also larger than that of CGIL $(\mathrm{p}<0.01)$.

There was no significant difference between the coefficients of variation of the VOR and VIR gains $(F(1,52)=1.22, p=0.27$ on the IL side, and $F(1,52)=0.085, p=0.77$ on the CL side). The coefficient of the BilCP group was the highest for both VIR and VOR, mostly for CL (i.e., CCW) rotations, as can be seen on Fig.3. 


\section{Discussion}

\section{VIR is excellent in control subjects}

The VIR gain of the control group was close to 1 and symmetrical.

It should be recalled that because of the trapezoid velocity profile of the stimuli, long plateaus of constant velocity (for the largest angles) were sometimes used. But cognitive mechanisms did probably fill in for the decaying vestibular signal, enabling subjects to perceive displacements longer than what the characteristics of the system would allow. The vestibular (and somatosensory) cue that must have arisen when the chair stopped at the end of a trial, mostly was interpreted as a signal to end the internally maintained percept of an ongoing rotation (Becker et al. 2000, 2002).

It should be noted that the angle imagery method in the present study is very different from Cousins et al.'s (2013) velocity estimation method, which was the perceived slowing of rotational velocity, more intuitive and probably more approximate than angle estimation. However a dissociation was found between VOR and vestibulo-perceptual response in the acute unilateral patients, with both methods. 
The imposed angles may seem too easy to estimate in our protocole, but everyone who

\section{VIR is correct in AcUCP ipsilateral}

The correct VIR gain on both sides in the unilateral patients groups is an important result of the present study. It generated a dissociation in the vestibular processing, since the VOR gain of the lesioned side was quite low.

The fact that the VIR gain in AcUCP, even IL, was close to the VIR gain in CG suggests several hypotheses :

A/ there is immediately after lesion either a central component of the vestibular compensation phenomenon (Allum and Ledin 1999; Fetter and Dichgans 1990) or a peripheral component with the otolith system (Maire and van Melle, 2000). However this hypothesis is not supported by Metcalfe and Gresty (1992), who did not find immediate central compensation phenomenon in their unilateral patients after complete vestibular nerve section.

$\mathrm{B} /$ perception uses both the excitation and the inhibition of lateral canals and does not need time for compensation as for the VOR. The possible extra-reflexive VIR pathway seems less lateralized than the reflexive VOR pathway : perception is not impaired like the VOR, as if the information transmitted by the two labyrinths would merge higher and would remain strong enough for the brain to rebuild perception. Cousins et al. (2013) asked whether a single labyrinth is capable of detecting motion in both directions, and the response is in the unilateral patients : when the lesioned side (IL) is stimulated, the healthy side (CL) is also stimulated. This is why the AcUCP and ChUCP groups had a correct VIR gain, by comparison with the BilCP.

So to explain the good VIR in the acute unilateral patients, we propose that the central pathways of rotation perception need information from both labyrinths, one safe and at least a weak input from the other one, in order to build good imagery immediately after lesion. VIR is the result of the stimulation of the two vestibules and consequently is not impaired in acute unilateral canal paresis. 


\section{VIR is affected only in BilCP}

There was no dissociation with the BilCP group, since this group had poor gains in both VIR and VOR.

The VIR gain of the BilCP group was lower than all the other groups, on both sides. In order to explain this low VIR gain in BilCP we suggest that it could be on both sides a consequence of a failure of the velocity storage mechanism (Raphan et al. 1979), which does not extend enough the vestibular stimulation during the longer velocity plateaus used in our test.

Furthermore, the compensation is not immediate and cannot be achieved even with time, when the two labyrinths are affected.

For the BilCP group the coefficients of variation (SD/mean) of both the VIR and VOR gains were larger than $50 \%$. This suggests that the patients were unsuccessfully trying to find complementary information, sensory or cognitive. Moreover this variation could exhibit a tired or a very tiring system between the differently efficient VIR and VOR, with recruitment followed by exhaustion.

According to Jandl et al. (2015), cerebellar activity during spatial navigation in BilCP patients may reflect increased non-vestibular eff orts to counteract navigation deficits. Jandl et al. suggested a change in navigational strategy of BilCP patients, from allocentric to more sequence-based.

\section{Correlation between the VOR and VIR gains.}

The correlation between VOR gain and VIR gain was examined, as did Kanayama et al. (1995). For ipsilateral stimulation, Kanayama et al. found significant correlations for selfrotation and vestibular remembered saccades versus VOR gain. But the feedback that the subjects received after each trial might have improved their responses and instigated the correlation. Great underestimates of passive rotations were found in the present experiment in patients with bilateral hyporeflexia, together with very low VOR gain. Furthermore a significant correlation between VOR gain and VIR gain was found, exclusively with the 
BilCP group. Thus VOR and VIR gains were indeed correlated, but only with the most deficient vestibular-lesioned patients.

This correlation may be the manifestation of increased recruitment for these subjects, who were looking for complementary information to assist their deficient vestibular information.

Acute vestibular vertigo induces a drastic mismatch between vestibular, visual and somatosensory signals, which may lead to distortions of the body schema (Lopez 2012). Indeed internal models govern perceptions, while simple filtering governs the human VOR (Merfeld et al., 2005). Thus qualitatively different mechanisms contribute to human VOR and perceptual responses. Furthermore vertigo probably adds a perceptual noise disturbing signal detection (Cousins et al. 2013). Indeed perceptual thresholds are higher than VOR thresholds, thus vestibular brainstem mechanisms are more sensitive to angular acceleration than cortical conscious mechanisms. This is why the search for a correlation between the perceptual response and the sensory reflex one is legitimate.

Moreover a different pathway might be recruited by the BilCP patients, as Hitier (2015) reports that four different pathways transmit vestibular information to the cortical centers involved in cognition. The BilCP group might be specifically concerned by the pathway close to the cerebellum, which receives direct projections from the vestibular nerve, since Jandle et al. (2015) suggested that patients with bilateral vestibular lesions rely on the cerebellum for spatial navigation.

Kyriakareli et al. (2013) measured thresholds of perception and slow phase velocity under galvanic stimulation. They found a larger threshold enhancement for VOR than for motion perception, indicating a partial dissociation between cortical processing of VOR and perceptual responses. We found in the present study that the BilCP group exhibited a low VOR and also a low VIR gain, but the AcUCP IL group had a low VOR and a correct VIR gain, thus we indeed found partial dissociation. 


\section{VOR}

While the VOR gain of AcUCP was very different between IL and CL sides, in ChUCP a symmetrical gain was observed. This was the effect of vestibular compensation (Fetter and Dichgans, 1990; Halmagyi et al. 1990; Maire and Melle 2000). Interestingly, the VOR gain of the IL side in ChUCP was higher than the VOR gain of the IL side in AcUCP, and inversely the VOR gain of healthy side of ChUCP was lower than the VOR gain of the healthy side of AcUCP (Fig.1). So both sides grew closer to each other, from AcUCP to ChUCP, in an attempt to balance the state of both semi-circular canals. As if vestibular compensation would lead to an increasing gain in lesion side and a decreasing gain in the healthy side (Maire and Melle 2000, Halmagyi et al. 1990).

The VOR gain of the BilCP group was low on both sides as expected since we included in this group patients with low responses in the caloric test and poor VOR gain in rotatory test.

Moreover, the VOR gains were close to those reported in the literature for healthy subjects (Clement et al. 2008; Baloh et al. 1986). Indeed the gain of the control group was considered normal in our experimental conditions : passive rotation in darkness without fixation and with a cognitive task (imagery of the travelled angle).

\section{Conclusion}

As it had been found that vestibular information contributes to update our internal visual maps (Israël et al. 1999), we here specify and broaden this vestibular imagery process. The present study shows the complex relationship between vestibular imagery and VOR, and our test could contribute to another assessment of the spatial handicap of vestibular patients. It seems particularly interesting for patients with bilateral canal paresis and could be used to confirm this diagnosis.

Spatial imagery can be vestibular, and we finally found a correlation between vestibular imagery and vestibular reflex, but this correlation appeared exclusively with bilaterally disordered vestibular patients. These patients might have tried to rely on imagery, less deficient than the VOR. Because imagery is intuitive, and does not need training. Indeed 
the task was very simple, even though it was not easy to respond accurately, and this is why BilCP was distinct from the other groups. It is also with an extremely simple task (counting seconds) that we had found a correlation between vestibular stimulation and time perception (Israël et al., 2004). But vestibular temporal imagery is beyond the scope of the present paper.

\section{Acknowledgments}

Alain Berthoz, professor at the Collège de France, is respectfully acknowledged for allowing us to realise this study with his motorised Barany chair.

The anonymous reviewer who amply contributed to improve the first version of this paper is gratefully acknowledged. 
Reference List

Allum JH, Ledin T (1999) Recovery of vestibulo-ocular reflex-function in subjects with an acute unilateral peripheral vestibular deficit. J.Vestib.Res. 9: 135-144

Baloh RW, Honrubia V, Yee RD, Hess K (1984) Changes in the human vestibuloocular reflex after loss of peripheral sensitivity. Ann.Neurol. 2: 222-228

Becker W, Jurgens R, Boss T (2000) Vestibular perception of self-rotation in different postures: a comparison between sitting and standing subjects. Exp.Brain Res. 131: 468-476

Becker W, Nasios G, Raab S, Jurgens R (2002) Fusion of vestibular and podokinesthetic information during self-turning towards instructed targets. Exp.Brain Res. 144: $458-474$

Besnard S, Lopez C, Brandt T, Denise P, Smith PF (2015) Editorial: The Vestibular System in Cognitive and Memory Processes in Mammalians. Front Integr.Neurosci. 9: 55

Bigelow RT, Agrawal Y (2015) Vestibular involvement in cognition: Visuospatial ability, attention, executive function, and memory. J.Vestib.Res. 25: 73-89

Clement G, Tilikete C, Courjon JH (2008) Retention of habituation of vestibulo-ocular reflex and sensation of rotation in humans. Exp.Brain Res. 190: 307-315

Cohen SB, Israël I Vestibular system and spatial orientation. Journal of Vestibular Research 14(2-3), 235. 2004.

Collewijn H (1989) The vestibulo-ocular reflex: an outdated concept. Progr.Brain Res. 80: 197-209

Cousins S, Kaski D, Cutfield N, Seemungal B, Golding JF, Gresty M, Glasauer S, Bronstein AM (2013) Vestibular perception following acute unilateral vestibular lesions. PLoS.ONE. 8: e61862 
Cutfield NJ, Cousins S, Seemungal BM, Gresty MA, Bronstein AM (2011) Vestibular perceptual thresholds to angular rotation in acute unilateral vestibular paresis and with galvanic stimulation. Ann.NY.Acad.Sci. 1233: 256-262

Etienne AS, Jeffery KJ (2004) Path integration in mammals. Hippocampus 14: 180192

Fetter M, Dichgans J (1990) Adaptive mechanisms of VOR compensation after unilateral peripheral vestibular lesions in humans. J.Vestib.Res. 1: 9-22

Guedry FE (1974) Psychophysics of vestibular sensation. In: Kornhuber HH (ed) Handbook of Sensory Physiology; Vol. VI/2. Springer Verlag, Berlin, Heidelberg, New York, pp 3-154

Halmagyi GM, Curthoys IS, Cremer PD, Henderson CJ, Todd MJ, Staples MJ, D'Cruz DM (1990) The human horizontal vestibulo-ocular reflex in response to high- acceleration stimulation before and after unilateral vestibular neurectomy. Exp.Brain Res. 81: 479-490

Hitier M, Besnard S, Smith PF (2014) Vestibular pathways involved in cognition. Front Integr.Neurosci. 8: 59

Israël I, Bronstein A, Kanayama R, Faldon M, Gresty MA (1996) Visual and vestibular factors influencing vestibular "navigation". Exp.Brain Res. 112: 411-419

Israël I, Ventre-Dominey J, Denise P (1999) Vestibular information contributes to update retinotopic maps. NeuroReport 10: 3479-3483

Israël I, Capelli A, Sable D, Laurent C, Lecoq C, Bredin J (2004) Multifactorial interactions involved in linear self-transport distance estimate: a place for time. Int.J.Psychophysiol. 53: 21-28

Israël I, Siegler I, Rivaud-Pechoux S, Gaymard B, Leboucher P, Ehrette M, Berthoz A, Pierrot-Deseilligny C, Flash T (2006) Reproduction of self-rotation duration. Neurosci.Lett. 402: $244-248$ 
Jandl NM, Sprenger A, Wojak JF, Gottlich M, Munte TF, Kramer UM, Helmchen C (2015) Dissociable cerebellar activity during spatial navigation and visual memory in bilateral vestibular failure. Neuroscience 305: 257-267

Kanayama R, Bronstein A, Gresty MA, Brookes GB, Faldon ME, Nakamura T (1995) Perceptual studies in patients with vestibular neurectomy. Acta Otolaryngol.(Stockh.) 115 Suppl. 520 PT 2: 408-411

Kyriakareli A, Cousins S, Pettorossi VE, Bronstein AM (2013) Effect of transcranial direct current stimulation on vestibular-ocular and vestibulo-perceptual thresholds. NeuroReport 24: 808-812

Lopez C, Schreyer HM, Preuss N, Mast FW (2012) Vestibular stimulation modifies the body schema. Neuropsychologia 50: 1830-1837

Lopez C (2013) A neuroscientific account of how vestibular disorders impair bodily self-consciousness. Front Integr.Neurosci. 7: 91

Maire R, Van Melle G (2000) Dynamic asymmetry of the vestibulo-ocular reflex in unilateral peripheral vestibular and cochleovestibular loss. Laryngoscope 110: 256-263

Merfeld DM, Park S, Gianna-Poulin C, Black FO, Wood S (2005) Vestibular perception and action employ qualitatively different mechanisms. II. VOR and perceptual responses during combined Tilt\&Translation. J.Neurophysiol. 94: 199-205

Mergner T, Rumberger A, Beckert W (1996) Is perceived angular displacement the time integral of perceived angular velocity ? Brain Res.Bull. 40: 467-470

Metcalfe T, Gresty MA (1992) Self-controlled reorienting movements in response to rotational displacements in normal subjects and patients with labyrinthine disease. Ann.NY Acad.Sci. 656: 695-698

Mittelstaedt ML, Mittelstaedt H (1980) Homing by path integration in a mammal. Naturwiss. 67: 566-567 
Nakamura T, Bronstein A (1995) The perception of head and neck angular displacement in normal and labyrinthine-defective subjects - A quantitative study using a 'remembered saccade' technique. Brain 118: 1157-1168

Okada T, Grunfeld E, Shallo-Hoffmann J, Bronstein A (1999) Vestibular perception of angular velocity in normal subjects and in patients with congenital nystagmus. Brain 122 ( Pt 7): 1293-1303

Raphan T, Matsuo V, Cohen B (1979) Velocity storage in the vestibulo-ocular reflex arc (VOR). Exp.Brain Res. 35: 229-248

Seemungal BM, Gunaratne IA, Fleming IO, Gresty MA, Bronstein AM (2004) Perceptual and nystagmic thresholds of vestibular function in yaw. J.Vestib.Res. 14: 461-466

Young LR (1984) Perception of the body in space : mechanisms. In: Darian-Smith I (ed) Handbook of Physiology - The nervous system III. American Physiological Society, Bethesda, pp 1023-1066 


\begin{tabular}{lcrrll}
\hline Groups & Number & Age & $\begin{array}{l}\text { Sex (male } \\
\text { ffemale) }\end{array}$ & Symptoms & $\begin{array}{l}\text { Inclusion criteria: } \\
\text { Caloric Test }\end{array}$ \\
\hline BilCP & 12 & $58(17)$ & $7 / 5$ & Dizziness & $\begin{array}{l}\text { Sum of the } 4 \text { responses } \\
<20 \% \mathrm{~s}\end{array}$ \\
AcUCP & 11 & $43.4(11)$ & $5 / 6$ & $\begin{array}{l}\text { Acute vertigo in the first } \\
\text { week }\end{array}$ & $\begin{array}{l}\text { Canal paresis asymmetry } \\
>80 \%\end{array}$ \\
ChUCP & 20 & $62.5(7)$ & $14 / 6$ & $\begin{array}{l}\text { Neuritis with dizziness } \\
\text { persistent }>3 \text { months }\end{array}$ & $\begin{array}{l}\text { Canal paresis remaining } \\
>60 \%\end{array}$ \\
CG & 13 & $51,5(17)$ & $6 / 7$ & $\begin{array}{l}\text { No otoneurologic } \\
\text { symptom now and before }\end{array}$ & $\begin{array}{l}\text { Symmetric with responses } \\
>10 \% \text { s for each ear }\end{array}$ \\
\hline
\end{tabular}

Ages are expressed as mean (SD) 
Figure captions

Fig.1 Mean VOR (vestibulo-ocular reflex) gain + standard deviation of the four groups, with IL (filled bars) and CL (striped bars) rotation directions. The X-axis indicates the group.

Fig.2 Mean VIR (vestibular imagery response) gain, same as Fig.1.

Fig.3 Scatter graph of the coefficients of variation of the VOR and the VIR gains, for the four groups. 


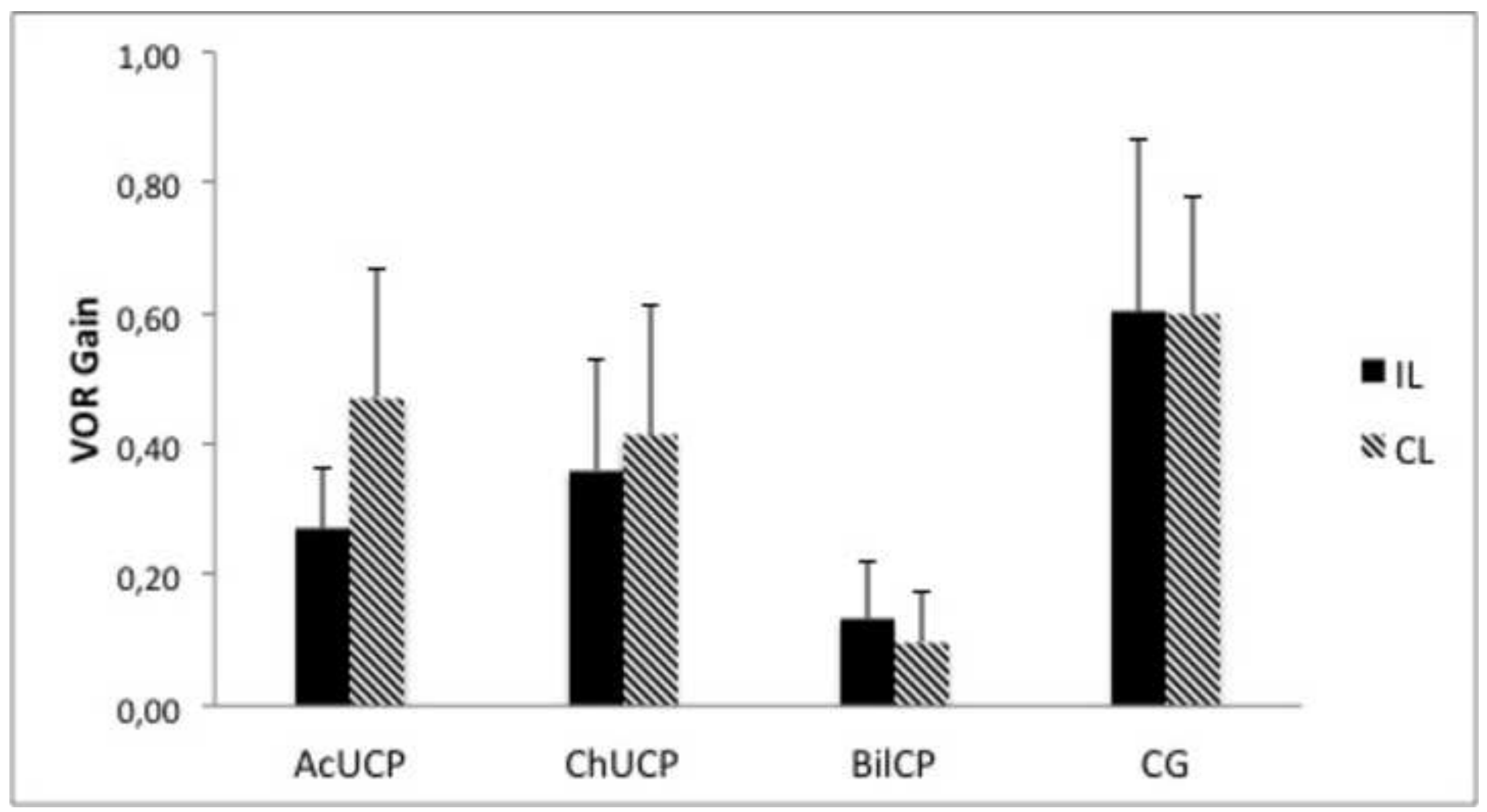




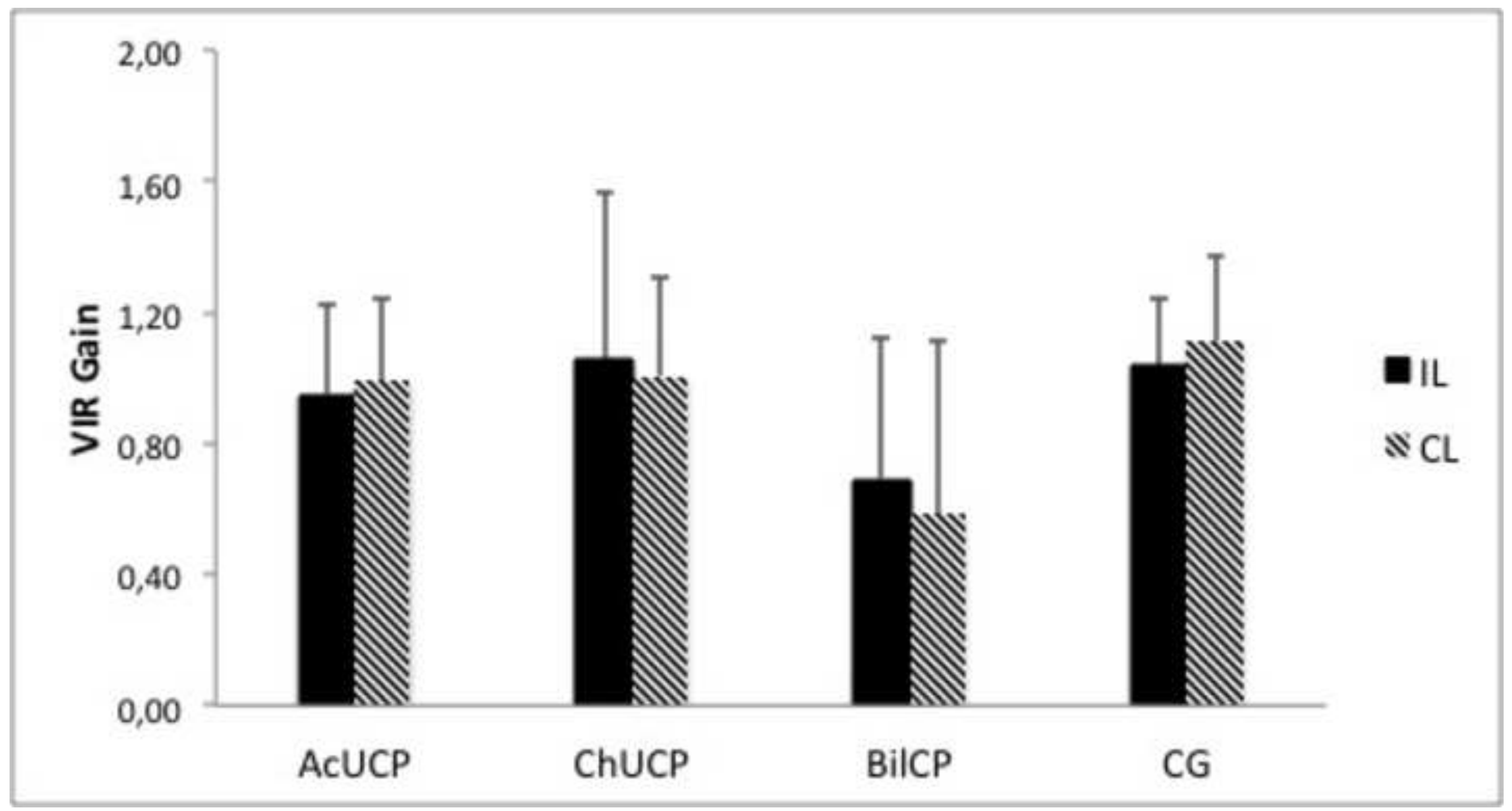




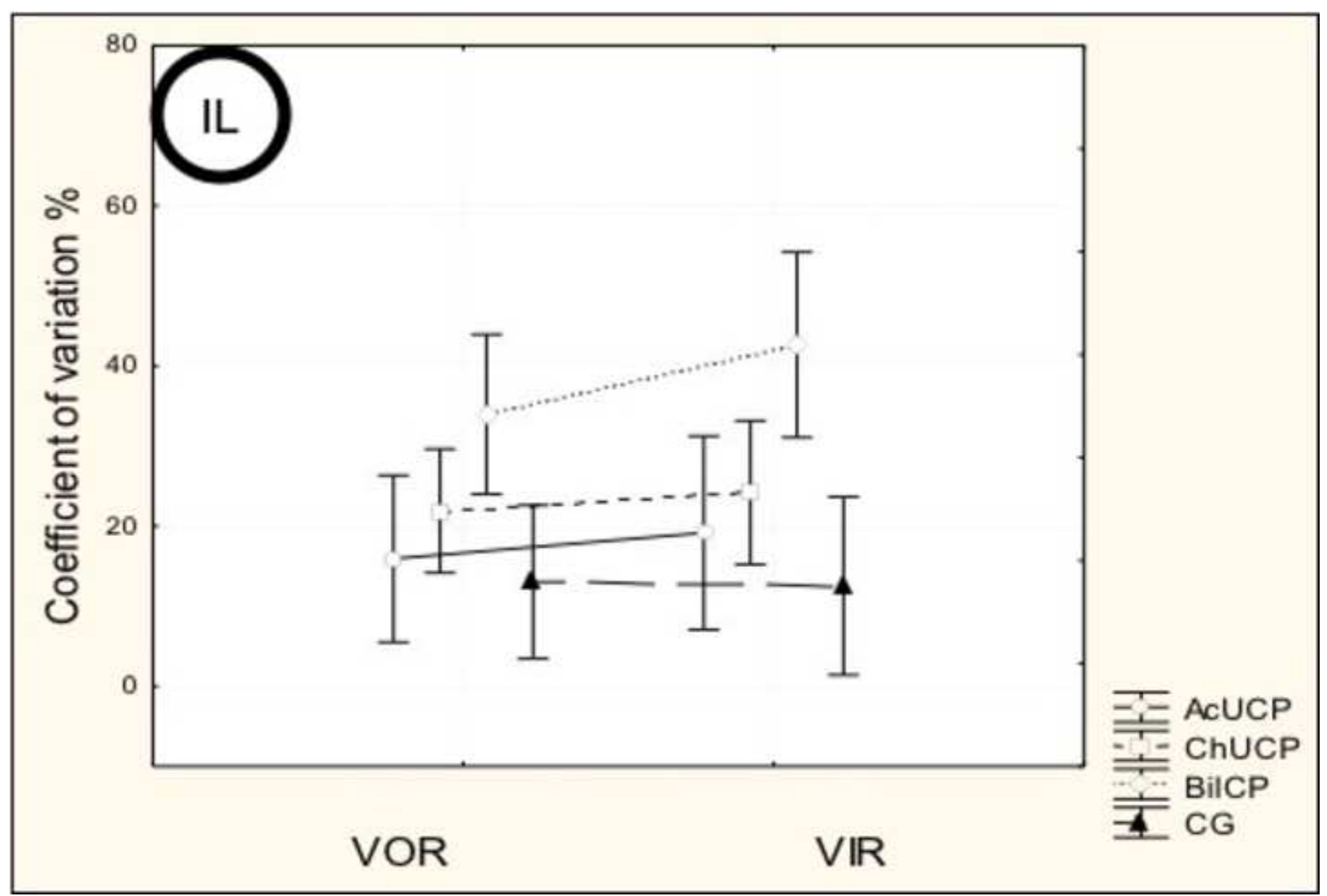




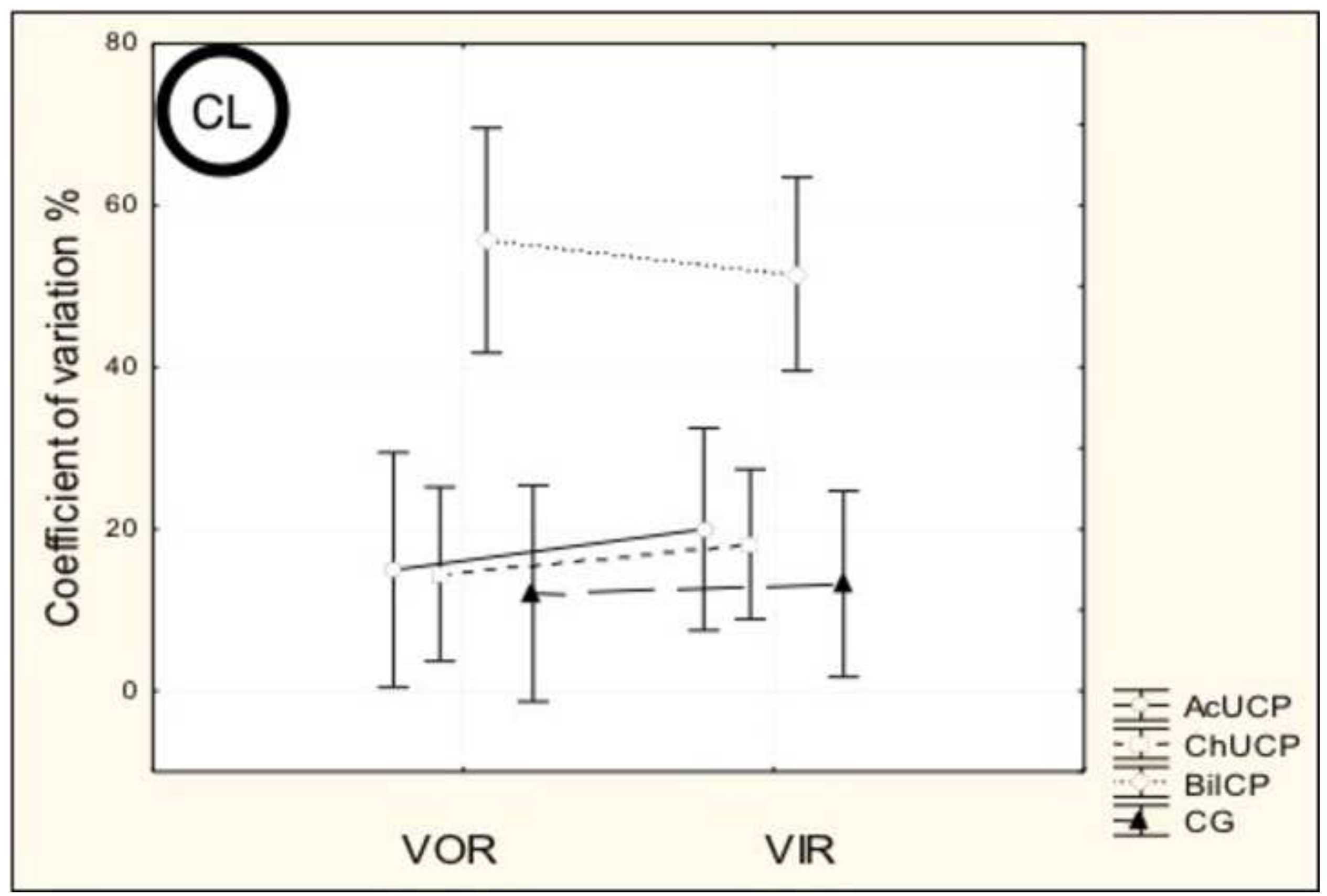

